\title{
Introductory Chapter: Dark Sides of Organizations and Leadership - An Integrative Approach and Definitions
}

\author{
Maria Fors Brandebo and Aida Alvinius \\ Additional information is available at the end of the chapter \\ http://dx.doi.org/10.5772/intechopen.81550
}

\section{Introduction}

The purpose of this introductory chapter is to define and integrate previous research on negative organizational structures and destructive leadership in order to understand how negative organizational features can be framing factors for negative leadership behavior. This is a necessary theoretical grip in order to fully understand the dark sides of organizational and individual behavior at the workplace in general.

Negative aspects of organizational structures have been previously studied in the area of management and organizational behavior and slightly within the area of destructive leadership [1-5]. However, the focus has primarily been either on the individual level or on the structures within the organization. For example, there are studies of the impact of adverse working conditions in terms of health [6] and job satisfaction [7]. Other studies focusing on individual organizational members suggest that organizational dysfunction is the result of dysfunctional individual behavior as shown in organizational settings [8]. Besides the impact of the individual on organizational challenges, the other widely studied aspect in relation to dysfunctional organizational aspects is organizational culture [9]. This is essentially an endogenous explanation. Researchers draw similarities between dysfunctional organizations and dysfunctional individuals arguing that culture is a pivotal factor in how organizations function internally. Similarly, organizational culture is seen in many studies as that which creates or destroys an organization [8]. Despite such interest and attempts to understand organizational culture and its role in managing organizational challenges, we still know little about the processes that spur dysfunctional organizational behavior - the exogenous factors-and how it affects individuals within the organization. 
Previous studies have primarily focused on the leader's impact on the ability of follower's acceptance of organizational change and management of organizational challenges [10]. Other researchers [11] suggest that leaders need to take a bigger responsibility and assume the role of chief architect of the organizational change process. But one question that remains is how organizational dark sides interplay with destructive leadership. First, we will provide a short presentation of organizational dark sides followed by definitions of destructive leadership.

\section{Dark sides of the organizational behavior}

Previous organizational studies have for decades focused on anorexic, narcissistic, and greedy organizations in order to explain organizational effectiveness and/or the well-being of the organizational members. Narcissistic organizations are characterized by many destructive behaviors denying facts about themselves or using propaganda campaigns. Organizations, just as humans, are able to develop justifications for their actions, to self-aggrandize by claiming their exclusivity, and so on. In anorexic organizations, staffing and material resources are kept to a minimum, and in greedy organizations, greater demands are made on individual stress coping, emotion management, competence, long working hours, constant availability, fixedterm employment contracts, and higher commitment. The common denominator for all three organizational dark sides is that organizations put high demands but offer their organizational members less in return. This can not only be a result of poor decision-making and destructive leadership but also as a consequence of political decisions, uncertainty, and insecurity outside the organization, bad organizational culture, and less transparency (see more information in [12]). Sometimes, negative organizational characteristics tend to be confused with destructive leadership behavior, as it is easier to look for scapegoats among individuals then for structural problems which may be the antecedents for negative organizational behavior. To avoid further confusion, we will provide contemporary definitions of destructive leadership.

\section{Destructive leadership}

There are several proposed definitions of destructive leadership. One of the first established definitions of destructive leadership was suggested by Einarsen and colleagues [3,13]. They state that destructive leadership could be defined as "the systematic and repeated behaviour by a leader, supervisor or manager that violates the legitimate interest of the organisation by undermining and/or sabotaging the organisation's goals, tasks, resources, and effectiveness and/or the motivation, well-being or job satisfaction of subordinates" ([3], p. 208). The definition was later developed by Krasikova, Green, and LeBreton [14] suggesting that destructive leadership should be regarded as harmful behavior imbedded in the process of leading (and by excluding behaviors falling under counterproductive work behavior), distinguishing between encouraging subordinates to follow destructive goals and using destructive methods to influence with subordinates, and by viewing destructive leadership as volitional behavior. Schyns and Schilling [15] proposed another definition arguing that destructive leadership is "a process in which over a longer period of time the activities, experiences and/or relationships 
of an individual or the members of a group are repeatedly influenced by their supervisor in a way that is perceived as hostile and/or obstructive" ([15], p. 141). As noticed, there is a disagreement about whether or not intent should be regarded when it comes to destructive leadership. Does the leader need to have a negative intent in order for the behavior to be perceived as destructive? Several researchers argue that the intent is of less importance. Rather, it is the consequences of the behavior that matter [16-18].

Another issue dividing the research field is whether passive leadership behaviors should be regarded as destructive. Some debate that a concept should not be defined by its consequences and that passive behaviors are ineffective, not destructive. Others call to attention the negative consequences of passive behaviors and, in the light of the view that intent is of less importance, argue that it is a form of destructive leadership; see, for example, $[16,18]$.

What are the underlying factors to why leaders engage in destructive leadership behaviors? For some leaders, the answers can be found in negative personality traits (e.g., narcissism or psychopathy). In other cases, stress and heavy workload have been suggested to be the reasons [16]. Therefore, leaders working in anorexic or greedy organizations may more often use destructive leadership behaviors. It has also been argued that organizational structures and norms can be the cause of destructive leadership. In these cases, the leader may not be prone to use destructive behaviors but the behaviors are rather a consequence of organizational structures, etc. It can be assumed that the occurrence of destructive leadership is more common in some organizations than in others. Research indicates that co-workers in hierarchical organizations (like the armed forces) have a more negative view of the organization if their immediate leader is a destructive leader. This is related to the leader's behavior being perceived to be sanctioned from higher leaders [15]. Research also suggests that destructive leadership is more common in organizations that are characterized by structural and organizational instability $[19,20]$, insecurity/perceived risk [21], and great freedom of action; in organizations with limited control mechanisms and high growth; and in rapidly transforming industries [22]. Organizations without established ethical norms and guidelines are also pinpointed as contributing to destructive leadership behaviors. In the light of these suggestions, it appears as organizational structures may be a contributing cause to why leaders use destructive leadership behaviors.

As shown above, there appear to be several relationships between organizational behavior and destructive leadership behaviors. However, the characteristics of these relationships needs more research. Do organizations "create" destructive leaders or do destructive leaders contribute to destructive organizations?

\section{Author details}

Maria Fors Brandebo* and Aida Alvinius

*Address all correspondence to: maria.forsbrandebo@fhs.se

Department of Security, Strategy and Leadership, Swedish Defence University, Stockholm, Sweden 


\section{References}

[1] Alvinius A, Johansson E, Larsson G. Negative organizations: Antecedents of negative leadership? In: Watola D, Woycheshin D, editors. Negative Leadership: International perspectives. Kingston: Canadian Defence Academy Press; 2016

[2] Caldwell C, Canuto-Carranco M. Organizational terrorism and moral choices exercising voice when the leader is the problem. Journal of Business Ethics. 2010;97:159-171

[3] Einarsen S, Aasland MS, Skogstad A. Destructive leadership behaviour: A definition and conceptual model. The Leadership Quarterly. 2007;18:207-216

[4] Fors Brandebo M. Military Leaders and Trust. Dissertation No. 2013:12, Faculty of Arts and Social Sciences Department of Social and Psychological Studies. Karlstad: Karlstad University Studies, 2015

[5] Larsson G, Fors Brandebo M, Nilsson S. Destrudo-L: Development of a short scale designed to measure destructive leadership behaviours in a military context. Leadership and Organization Development Journal. 2012;33:383-400

[6] Larsson G, Berglund AK, Ohlsson A. Daily hassles, their antecedents and outcomes among professional first responders: A systematic literature review. Scandinavian Journal of Psychology. 2016;57(4):359-367

[7] Alpass F, Long N, Chamberlain K, MacDonald C. Job satisfaction differences between military and ex-military personnel: The role of demographic and organizational variables. Military Psychology. 1997;9:227-249

[8] Alemu DS. Dysfunctional organization: The leadership factor. Open Journal of Leadership. 2016;5(01):1

[9] Balthazard PA, Cooke RA, Potter RE. Dysfunctional culture, dysfunctional organization: Capturing the behavioral norms that form organizational culture and drive performance. Journal of Managerial Psychology. 2006;21:709-732

[10] Kavanagh MH, Ashkanasy NM. The impact of leadership and change management strategy on organizational culture and individual acceptance of change during a merger. British Journal of Management. 2006;17(S1):S81-S103

[11] Nadler DA, Thies PK, Nadler MB. Culture change in the strategic enterprise: Lessons from the field. In: Cooper CL, Carwright S, Earley PC, editors. The International Handbook of Organizational Culture and Climate. Chichester: John Wiley \& Sons Ltd; 2001

[12] Alvinius A, Ohlsson A, Larsson G. Organizational challenges and leader's coping strategies-A qualitative study of Swedish military staff-organization. Journal of Military Studies. 2017:1-10. Retrived from: https://content.sciendo.com/view/journals/jms/aheadof-print/article-10.1515-jms-2017-0002.xml 
[13] Skogstad A, Einarsen S, Torsheim T, Aasland MS, Hetland H. The destructiveness of laissez-faire leadership behavior. Journal of Occupational Health Psychology. 2007;12(1):80

[14] Krasikova DV, Green SG, LeBreton JM. Destructive leadership: A theoretical review, integration, and future research agenda. Journal of Management. 2013;39(5):1308-1338

[15] Schyns B, Schilling J. How bad are the effects of bad leaders?: A meta-analysis of destructive leadership and its outcomes. The Leadership Quarterly. 2013;24(1):138-158

[16] Fors Brandebo M, Nilsson S, Larsson G. Leadership: Is bad stronger than good? Leadership and Organization Development Journal. 2016;37(6):690-710

[17] Fors Brandebo M, Österberg J, Berglund AK. The impact of constructive and destructive leadership on soldier's job satisfaction. Psychological Reports. 2018:1-19

[18] Skogstad A, Birkeland Nielsen M, Einarsen S. Destructive forms of leadership and their relationships with employee well-being. In: Kelloway K, Nielsen K, Dimoff JK, editors. Leading to Occupational Health and Safety: How Leadership Behaviours Impact Organizational Safety and Well-being. West Sussex, UK; John Wiley \& Sons Ltd; 2017

[19] Conger JA, Kanungo RN. Toward a behavioral theory of charismatic leadership in organizational settings. Academy of Management. 1987;12(4):637-647

[20] Padilla A, Hogan R, Kaiser RB. The toxic triangle: Destructive leaders, susceptible followers, and conducive environments. The Leadership Quarterly. 2007;18:176-194

[21] Solomon S, Greenberg J, Pyszczynski T. A terror management theory of social behavior: The psychological functions of self-esteem and cultural worldviews. Advances in Experimental Social Psychology. 1991;24:93-159

[22] Hambric DC, Abrahamson E. Assessing managerial discretion across industries: A multi method approach. Academy of Management Journal. 2017;35(5):1427-1441

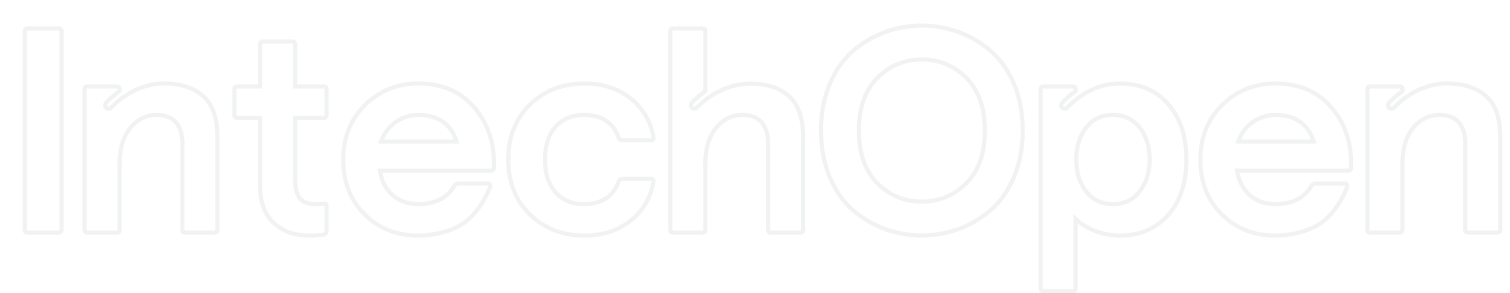



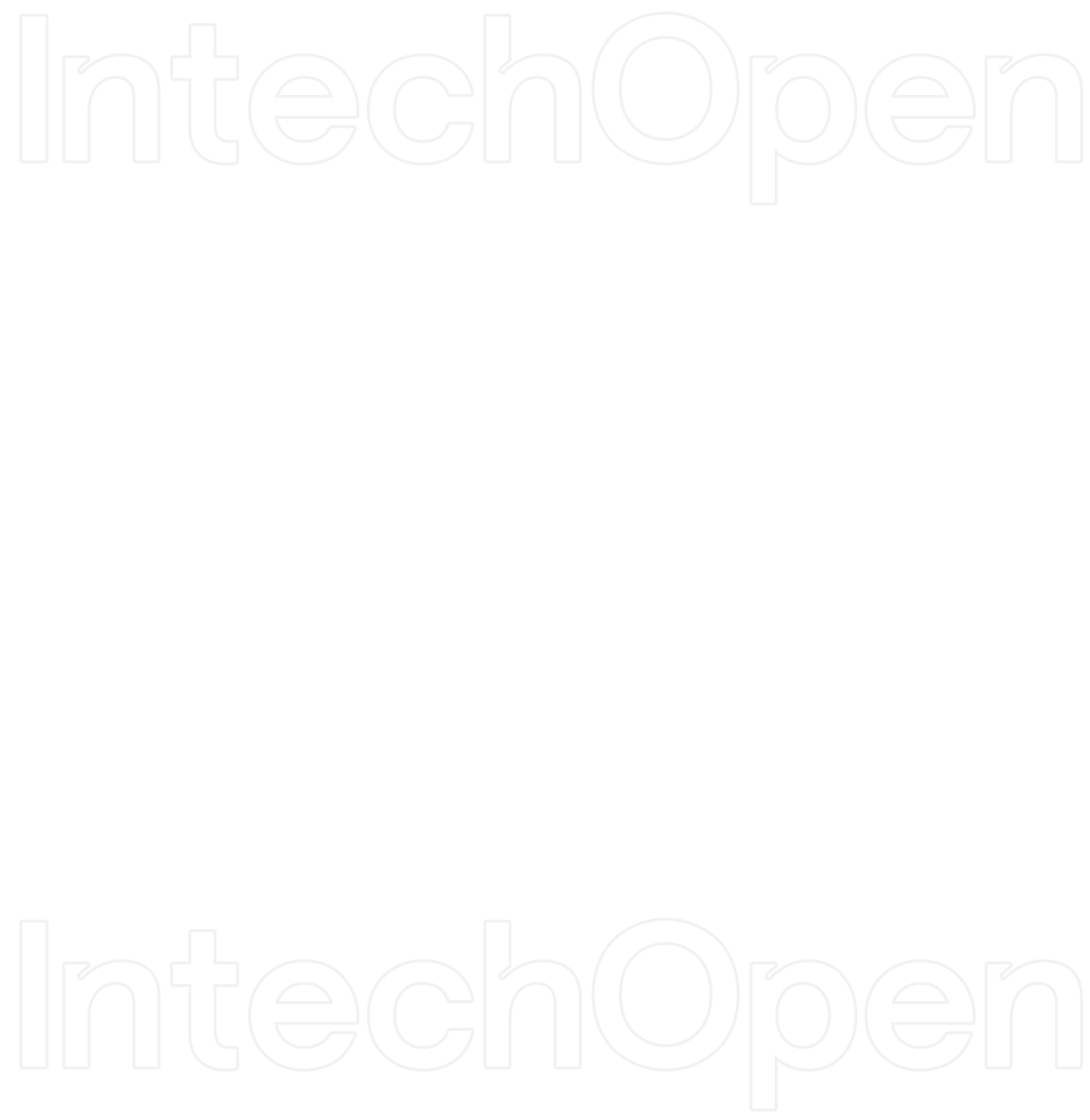